\title{
p53 inhibits SP7/Osterix activity in the transcriptional program of osteoblast differentiation
}

\author{
Natalia Artigas ${ }^{1}$, Beatriz Gámez ${ }^{1}$, Mónica Cubillos-Rojas ${ }^{1}$, Cristina Sánchez-de Diego ${ }^{1}$, José Antonio Valer ${ }^{1}$, Gabriel Pons ${ }^{1}$, \\ José Luis Rosa ${ }^{1}$ and Francesc Ventura,
}

Osteoblast differentiation is achieved by activating a transcriptional network in which D/x5, Runx2 and Osx/SP7 have fundamental roles. The tumour suppressor p53 exerts a repressive effect on bone development and remodelling through an unknown mechanism that inhibits the osteoblast differentiation programme. Here we report a physical and functional interaction between Osx and p53 gene products. Physical interaction was found between overexpressed proteins and involved a region adjacent to the OSX zinc fingers and the DNA-binding domain of p53. This interaction results in a p53-mediated repression of OSX transcriptional activity leading to a downregulation of the osteogenic programme. Moreover, we show that p53 is also able to repress key osteoblastic genes in Runx2-deficient osteoblasts. The ability of p53 to suppress osteogenesis is independent of its DNA recognition ability but requires a native conformation of $\mathrm{p} 53$, as a conformational missense mutant failed to inhibit OSX. Our data further demonstrates that 553 inhibits OSX binding to their responsive Sp1/GC-rich sites in the promoters of their osteogenic target genes, such as IBSP or COL1A1. Moreover, p53 interaction to OSX sequesters OSX from binding to DLX5. This competition blocks the ability of OSX to act as a cofactor of DLX5 to activate homeodomain-containing promoters. Altogether, our data support a model wherein p53 represses OSX-DNA binding and DLX5-OSX interaction, and thereby deregulates the osteogenic transcriptional network. This mechanism might have relevant roles in bone pathologies associated to osteosarcomas and ageing. Cell Death and Differentiation (2017) 24, 2022-2031; doi:10.1038/cdd.2017.113; published online 4 August 2017

Osteoblast differentiation is triggered by a variety of intra- and extracellular osteogenic signals, such as BMPs, IGFs and Wnts. ${ }^{1}$ The process commences with a mesenchymal stem cell (MSC) precursor becoming an osteochondroprogenitor cell, which is later sequentially transformed into a mature osteoblast.

It is also well known that osteochondroprogenitor maturation and the subsequent conversion of pre-osteoblasts to mature osteoblasts is controlled by a network of specific transcription factors. Among these, Runx2 and Osterix/SP7 (Osx) have a critical role in osteogenesis. ${ }^{2,3}$ Runx2 deletion in mice causes a severe impairment in the development of the skeleton and Runx2 mutations in humans are causative of cleidocranial dysplasia disorder. ${ }^{4}$ Similarly, Osx deletion impairs the consecution of a mature osteoblast phenotype and was proven to be important in the maintenance of bone homeostasis, because its postnatal deletion causes loss of bone mass and bone defects. ${ }^{5,6}$ Several studies also found that SP7/Osx mutations or SNPs are related to osteoporosis and osteogenesis imperfecta. ${ }^{7,8}$ For these reasons, Osx and Runx2 are mandatory for the development of the skeleton. Moreover, both cooperatively regulate the expression of key genes in bone biology forming a transcriptional complex. ${ }^{9}$ OSX also acts as a necessary cofactor for DLX family of transcription factors. ${ }^{10}$ Furthermore, these transcription factors are subjected to fine tuning by posttranscriptional regulation. For instance, MAP kinases phosphorylate DLX5, RUNX2 and OSX, leading to their activation. ${ }^{11-13}$ These studies highlighted the complexity of the transcription factor network, which controls the osteoblast differentiation process and bone development.

Maturation of MSCs to the osteoblastic phenotype is a multistep process that requires cell expansion, differentiation and survival. The tumour suppressor p53 is considered a master regulator of proliferation and apoptosis. p53 activity helps to eliminate damaged cells, preventing tumorigenesis. ${ }^{14}$ Furthermore, p53 has been linked to cell differentiation in a variety of cell types, such as neurons, muscular cells and osteoblasts. ${ }^{15-17}$ Surprisingly, despite the key cellular functions of p53, Trp53 knockout mice did not show major developmental defects. However, detailed studies demonstrated skeletal abnormalities in some animals, such as upper incisor fusion and craniofacial and limb malformations. ${ }^{18}$ Trp53 knockout mice are also characterized by a denser skeleton than their wild-type littermates and the Trp53deficient bone marrow-derived MSCs (BM-MSCs) have a higher capacity to differentiate towards the osteoblastic fate. ${ }^{17,19}$ The impact of $p 53$ on the osteoblastic transcription factor network is also evident, as cells with the Trp53 deletion overexpress Osx and osteogenic genes through an unknown mechanism. ${ }^{17}$

Previous studies suggested that p53 deletion allows overactivation of the BMP pathway by mechanisms that involve changes in the expression of Smad1 or Smurf1. ${ }^{20,21}$ It has also been shown that p53 and RUNX2 proteins interact, blocking Runx2 transcriptional activity, and that p53 regulates Runx2

${ }^{1}$ Departament de Ciències Fisiològiques, Universitat de Barcelona, IDIBELL, L'Hospitalet de Llobregat, Spain

${ }^{*}$ Corresponding author: Francesc Ventura, Departament de Ciències Fisiològiques, Universitat de Barcelona, IDIBELL, C/Feixa Llarga s/n, E-08907 L'Hospitalet de Llobregat, Spain. Tel: +34 934024281; Fax: +34 934024268; E-mail: fventura@ub.edu

Received 23.9.16; revised 21.4.17; accepted 12.6.17; Edited by S Fulda; published online 04.8.17 
expression levels by an miRNA-mediated mechanism. ${ }^{22,23}$ Therefore, although the inhibitory role of $\mathrm{p} 53$ in bone formation is well established, little is yet known about the molecular mechanisms by which p53 exerts this function. Moreover, an in-depth understanding of the role of p53 in bone biology could have implications in the knowledge of pathologies associated with p53 signalling network alterations.

Our work focused in the identification of the molecular mechanisms by which p53 exerts a repressive effect over the osteoblast differentiation programme. We found, using either loss- or gain-of-function models, that p53 expression has a negative impact on the expression of osteoblast-specific transcription factors and their targets. Our work further demonstrated that the negative role of p53 is independent of p53 transcriptional activity but instead required physical interaction between OSX and p53 at the protein level. p53 prevented OSX from binding to Sp1/GC-rich sequences and blocked OSX from interacting with DLX5 and binding to homeodomain sequences.

\section{Results}

p53 downregulates osteoblastic gene expression. It has been previously established that p53 has an inhibitory role in osteoblast differentiation using mouse models. ${ }^{17,24}$ There is also evidences suggesting that these phenotypes are cell autonomous, as the BM-MSCs from p53-deficient mice show enhanced differentiation in vitro. ${ }^{19}$ To further characterize the molecular mechanism underlying these phenotypes, we first evaluated osteoblastic gene expression from primary osteoblasts obtained from Trp53 knockout or wild-type mice. Absence of p53 results in upregulation of important genes implicated in bone development (Figure 1a). Importantly, two transcription factors with relevant roles in bone biology, $D / x 5$ and $O s x,^{11,25}$ were 2-fold and 3.5-fold overexpressed, respectively. Furthermore, Runx2 showed a slight upregulation at the mRNA level. OSX target genes were also upregulated in Trp53 knockout osteoblasts, such as Ibsp (bone sialoprotein) or Bglap (osteocalcin). ${ }^{9,26,27}$

To confirm these results, we used the p53-inducible SaOs2 cell line SaOs2-p53TetOn, which only expresses p53 upon the addition of doxycycline (Figure 1b). Treatment with doxycycline for $24 \mathrm{~h}$ confirmed the p53-dependent inhibition of OSX, $D L X 5, I B S P$ and $C O L 1 A 1$ expression. The upregulation of $B G L A P$ expression after induction of p53 expression could be explained by direct binding of p53 to the known p53responsive sequences in $B G L A P$ promoter. ${ }^{28,29}$ These results provide evidence of a p53-dependent downregulation of the expression of osteoblastic genes.

As previous studies had identified the involvement of the osteogenic BMP pathway on p53's effects, we next focused on this signalling pathway and its modulation by p53. As previously reported, p53 deletion results in a slight upregulation of Smad1 mRNA, as well as the BMP-target gene Id1 in primary osteoblasts 16,30 (Supplementary Figure 1A, left panel). Interestingly, an induction of Smad7 was found in p53 knockout osteoblast. In accordance a 1.4-fold upregulation of $S M A D 7$ expression was obtained after induction of p53
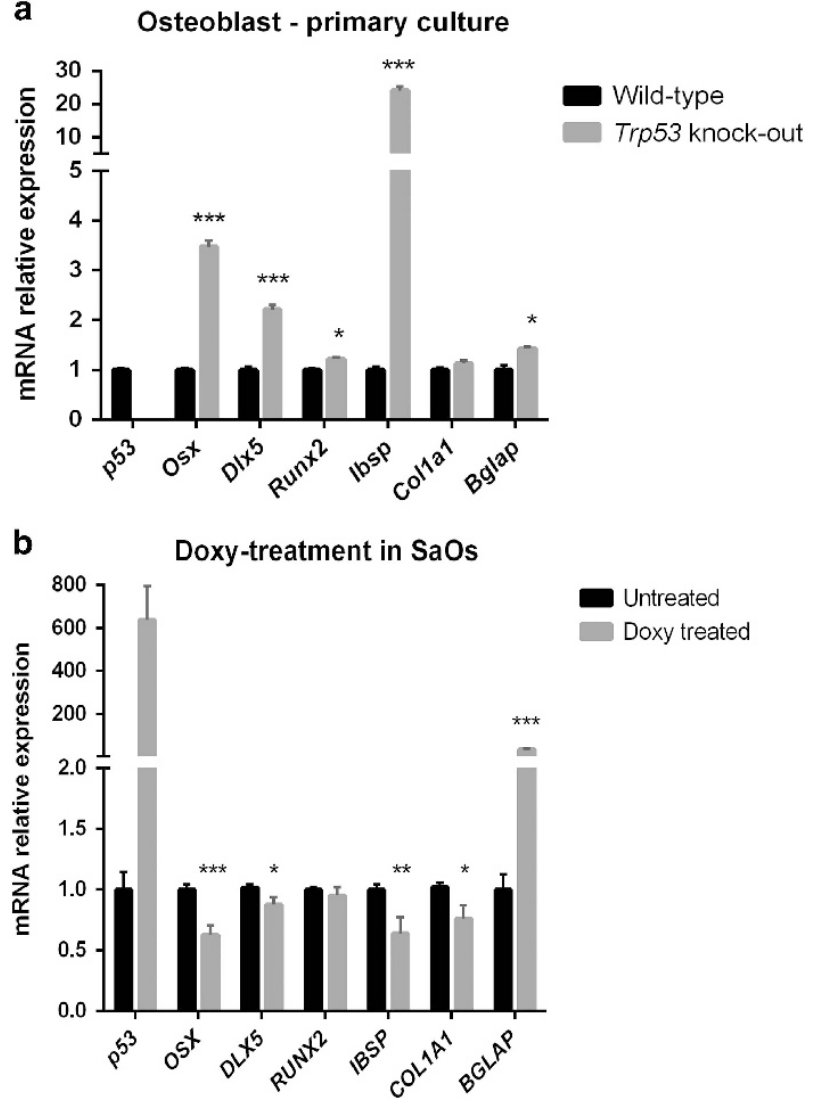

Figure 1 p53 protein inhibits osteogenic differentiation transcriptional programme. (a) mRNA expression levels of primary osteoblasts from wild-type or Trp53 knockout mice grown for 3 days in osteogenic differentiation medium, and (b) SaOs2p53TetOn were treated for $24 \mathrm{~h}$ with doxycycline $2 \mathrm{nM}$ in 1\% FBS medium. Bglap indicates Osteocalcin gene mRNA. mRNAs were measured by RT-qPCR, normalized to $T B P$ and expressed as relative expression \pm S.E.M. of at least three independent experiments $\left({ }^{\star} P<0.05,{ }^{* *} P<0.01,{ }^{* * *} P<0.001\right.$, using the Student's $t$-test)

in SaOs2 cells, but no substantial changes in the expression of SMAD1 or ID1 (Supplementary Figure 1A, right panel).

SaOs2-p53TetOn cells were also incubated with doxycycline for $16 \mathrm{~h}$ and treated with $2 \mathrm{nM}$ BMP2 for $2 \mathrm{~h}$. Our results failed to detect significant differences in pSMAD1/5/8 levels in either primary osteoblasts or the SaOs2-p53TetOn model (Supplementary Figures 1B and C). Moreover, expression of genes such as JUNB, SMAD7 or DLX5, which are direct targets of Smad-transcription factors, was independent of p53 induction and only ID1 displayed a minor downregulation in the doxycycline-treated condition (Supplementary Figure 1D). Thus, these minor negative effects of p53 on the BMP pathway likely could not explain the changes observed in osteogenic gene expression.

p53 physically interacts with Osx. In order to identify the mechanisms involved in inhibition of osteogenic gene expression by p53 we focused on two drivers of bone development, RUNX2 and OSX. As a mechanism by which p53 inhibits RUNX2 through physical interaction has been described previously in a DNA-damage context, ${ }^{22}$ we also tested the capacity of p53 to bind to RUNX2 and OSX. To 
a

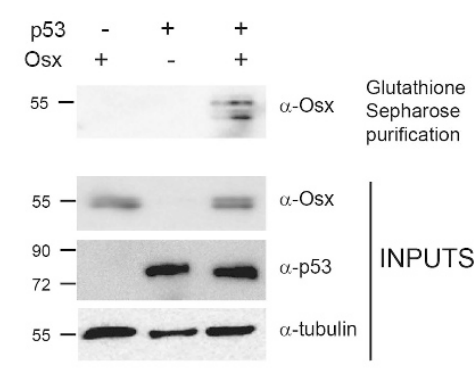

d
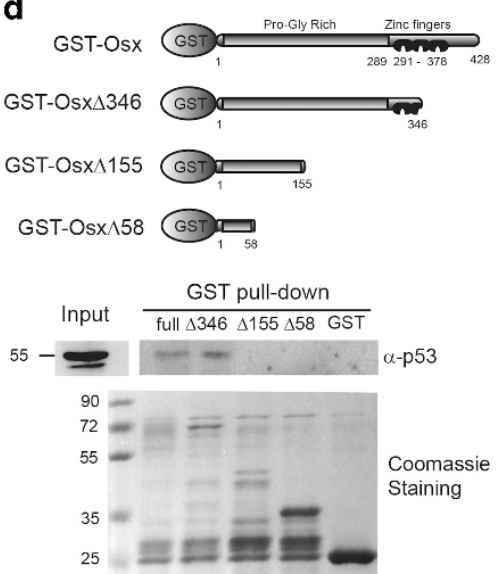

b
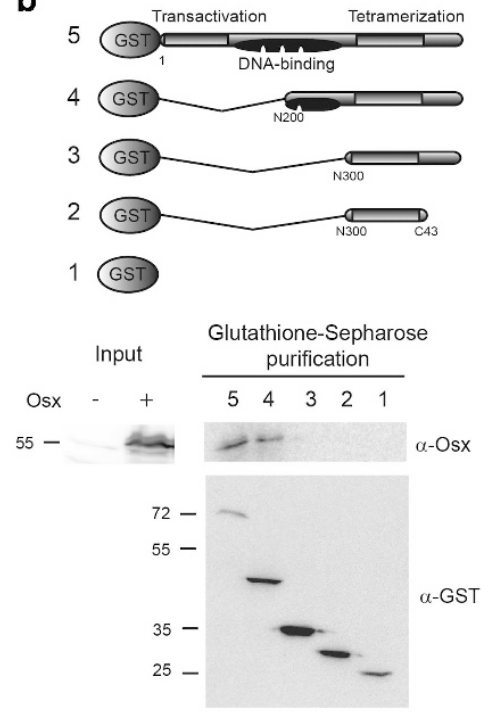

e
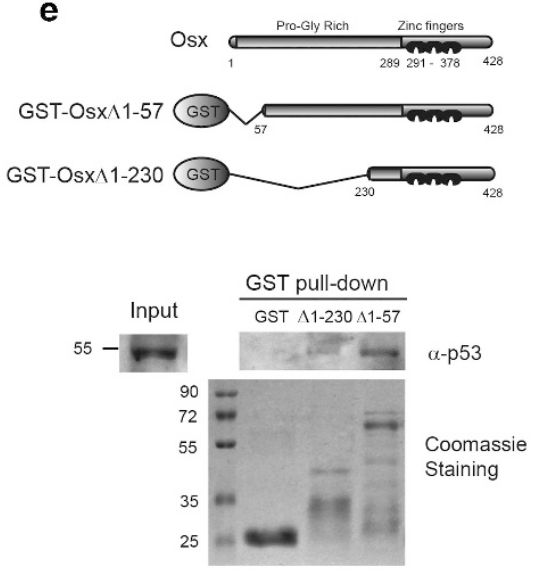

C
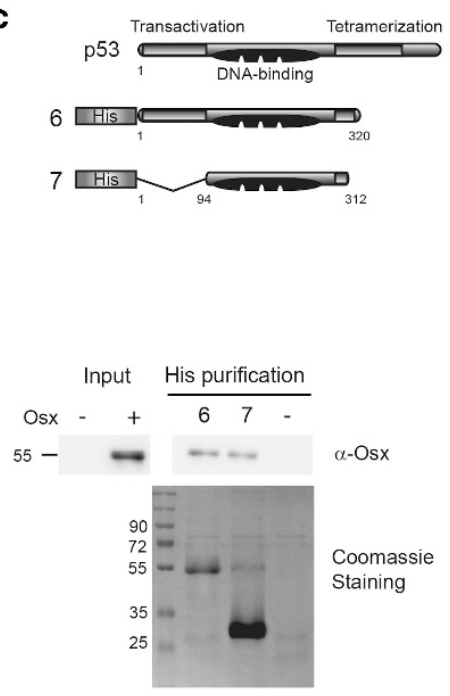

f

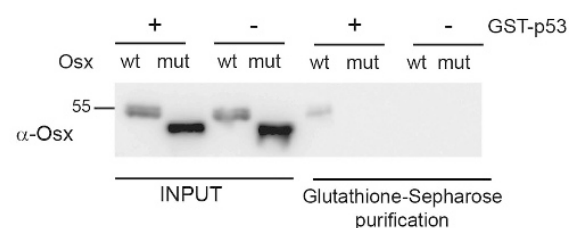

Figure 2 p53 protein physically interacts with OSX. (a) SaOs2 cells were infected with retroviral expression vectors for human Osx and/or GST-tagged human p53. Extracts from cells and Glutathione-Sepharose co-precipitated proteins were visualised by immunoblotting using anti-p53 and anti-Osx antibodies. (b) Extracts from HEK293T cells transfected with Osx expression vector in combination with the indicated GST-p53-chimeric protein were incubated with Glutathione-Sepharose beads for $1 \mathrm{~h}$. Co-precipitated proteins were identified by immunoblotting using anti-OSX antibody. (c-e) Cell extracts were incubated with the indicated chimeric protein bound to Glutathione-Sepharose (d and e) or $\mathrm{Ni}^{2+}$ (c) beads overnight. Interacting proteins were identified by immunoblotting using anti-p53 or anti-OSX antibodies. (f) Lysates from HEK293T cells expressing murine wild-type Osx or the double mutant S73A/S77A in combination with the p53-chimeric protein or GST were incubated with Glutathione-Sepharose beads. Interacting proteins were identified by immunoblotting using anti-OSX antibody

assess this, we retrovirally infected SaOs2 cells with OSX and GST-tagged p53 expression vectors. OSX co-purified with p53, suggesting that they interact in osteogenic cells (Figure 2a). To map the involved interaction sites, we expressed Osx in combination with different truncated GSTp53 expression vectors in mammalian cells. OSX was able to bind to the $\mathrm{N}$-terminal region of p53 protein in intact cells (Figure 2b). We further pinpoint the p53 domain involved in such interaction by studying OSX binding to recombinant $\mathrm{N}$-terminal truncated p53 (Figure 2c). Altogether, the data demonstrate that the p53 DNA-binding domain is sufficient for physical interaction with OSX. We also verified which domain of OSX was involved in the interaction. Our results showed that $\mathrm{p53}$ requires a region that encompasses part of the transactivation domain proximal to the OSX zinc fingers
(Figures 2d and e). We also determined whether the activation status of OSX influences its interaction with p53. A less active form of OSX (the OSX S73A/S77A mutant, which cannot be phosphorylated by MAP kinases) showed lower interaction with p53 in intact cells (Figure 2f).

Similar assays with GST-p53 expression vectors showed that RUNX2 was able to bind to the $\mathrm{N}$-terminal domain of p53 in mammalian cells (Supplementary Figure 2A). Recombinant truncated RUNX2 proteins showed that RUNX2 requires the PST region to physically interact with p53 (Supplementary Figure 2B).

Osx transcriptional activity is inhibited by interaction with p53. We next assessed the effect of p53 interaction on OSX transcriptional activity. We evaluated the expression 


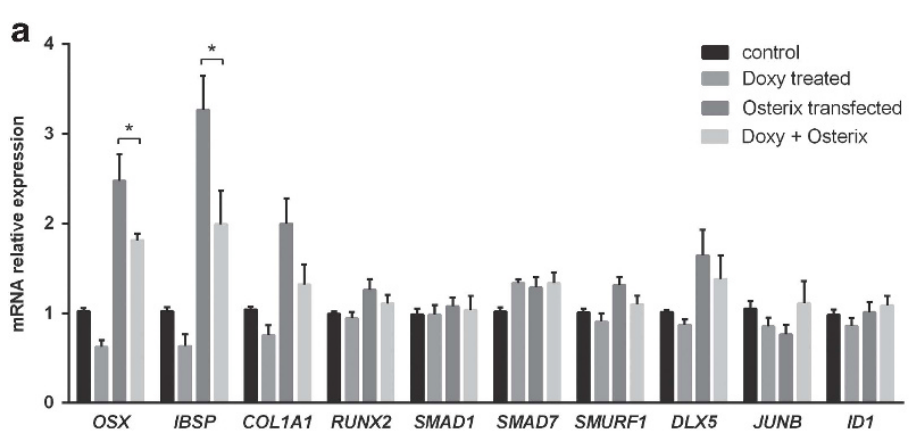

b

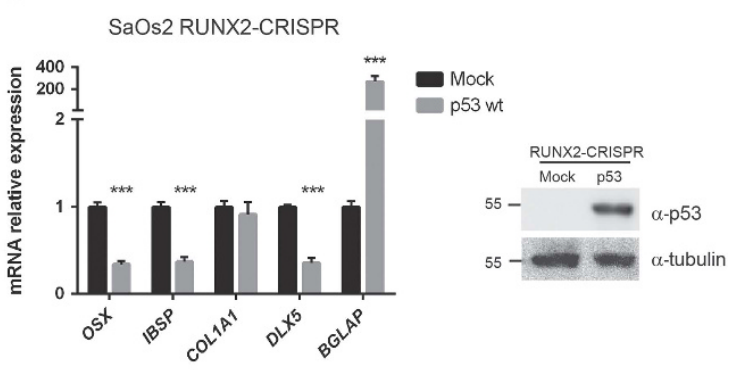

c

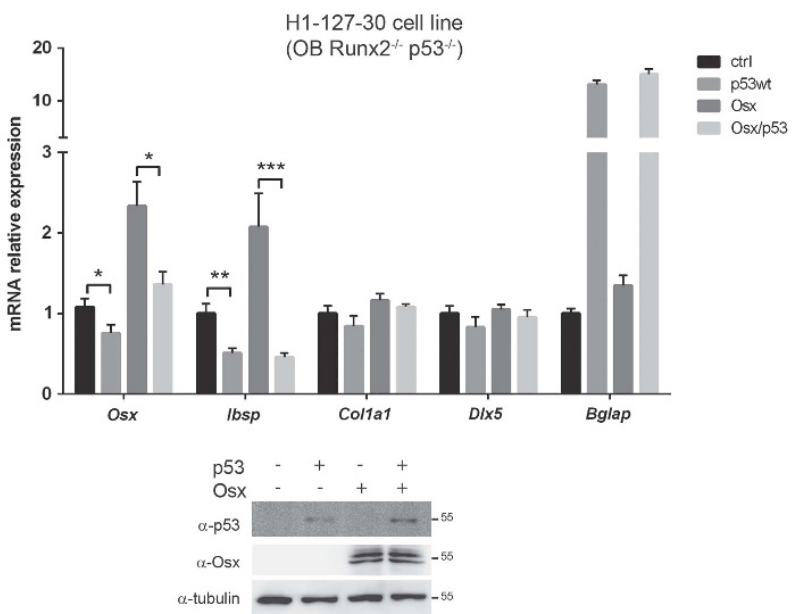

d

d SaOs-2 $+p 53 \quad+p 53$

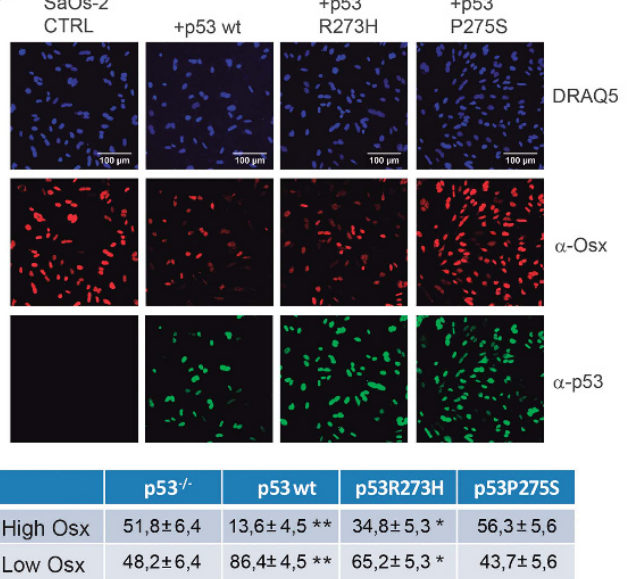

Figure 3 p53 regulates osteoblastic gene expression inhibiting OSX transcriptional activity. (a) mRNA expression levels in SaOs2-p53TetOn treated for $24 \mathrm{~h}$ with $2 \mathrm{nM}$ doxycycline and/or transfected with Osx expression vector. mRNA was measured by qRT-PCR, normalized to TBP and expressed as relative expression \pm S.E.M. of at least three independent experiments. (b) mRNA expression levels in SaOs2 RUNX2-CRISPR cells retrovirally infected with murine p53 expression vector. Right panel shows a western blotting to verify p53 expression. (c) H1-127-30 osteoblasts generated from the double Runx2 and Trp53 knockout mice were infected with retroviral expression vectors for murine p53 and OSX. mRNAs were measured by RT-qPCR, normalized to TBP and expressed as relative expression \pm S.E.M. from six independent experiments. (d) Immunocytofluorescence of SaOs2 cells infected with retroviral expression vectors carrying murine p53 wild type, human p53R273H and murine p53P275S. Immunostaining was performed with anti-OSX and anti-p53 antibodies and nuclei visualized using DRAQ5. Quantification of OSX relative expression levels (cut-off point at $<150$ OSX intensity) are expressed as percentage of cells. Statistics were performed against the p53 knockout condition. $\left({ }^{\star} P<0.05,{ }^{* *} P<0.01,{ }^{* *} P<0.001\right.$ using the Student's $t$-test)

of genes implicated in the osteoblastic differentiation programme on SaOs2-p53TetOn cells overexpressing OSX in combination with doxycycline treatment (Figure 3a). Both controls and cells overexpressing OSX had a lower induction of OSX target genes (such as OSX itself and $I B S P^{27,31}$ ) when p53 was expressed. The qPCR assay only detected endogenous OSX expression; thus, these data provide additional evidence of OSX regulation of its own promoter. ${ }^{31}$ These observations suggest that OSX transcriptional activity is inhibited by $\mathrm{p} 53$.

p53 has been shown to repress RUNX2 function. ${ }^{23}$ For this reason, we then analyzed whether the effects of p53 on osteogenic gene expression were derived from inhibition of RUNX2 or also depended on the inhibition of OSX transcriptional activity. Two distinct approaches were performed: first, generation of pools of SaOs2 cells, which are p53-deficient, where the third exon of the RUNX2 gene was inactivated by CRISPR technology (Supplementary Figure 3A). Second, analysis of the osteoblast cell line $\mathrm{H} 1-127-30$ generated from the double Runx2/p53 knockout mice. ${ }^{32}$ The RUNX2-specific CRISPR deletion was confirmed by immunoblot, obtaining a pool of cells with $60 \%$ reduction of RUNX2 levels
(Supplementary Figure 3B). Expression of p53 in these cells still conferred a strong downregulation of osteogenic genes (Figure 3b). Similarly, re-expression of p53 in Runx2 $2^{\prime-}$ $p 53^{-1-}$ osteoblasts led to inhibition of Osx and Ibsp expression, and abolished their induction by ectopic OSX (Figure 3c). Altogether, these data suggest that the inhibitory effects of p53 on osteogenic gene expression depend not only on RUNX2 but also on OSX inhibition.

We also analyzed by immunofluorescence whether p53 could block OSX trafficking to the nucleus. First, we visualized that OSX expression in SaOs2-p53TetOn cells was localized in the nucleus regardless of p53 expression. Second, at the single-cell level the expression of p53 was negatively correlated with that of OSX (Supplementary Figure 4). To further confirm the negative correlation between p53 and OSX protein levels, we infected p53-deficient SaOs2 cells with retrovirus expressing murine wild-type p53, the human contact mutant p53R273H or the murine structural mutant p53P275S. Whereas the p53R273H changes the Arg273 involved in base recognition, p53P275S (corresponding to P278S in the human p53 gene) alters the structure of the its DNA-binding domain. ${ }^{33-35}$ Expression of wild-type p53 or the p53R273H 
mutant induced a strong downregulation of endogenous OSX expression, whereas the p53P275S mutant did not significantly changed OSX levels (Figure $3 d$ ).

Osx-DNA binding is blocked by p53 protein. A mechanism by which $\mathrm{p} 53$ could inhibit OSX transcriptional activity could be affecting its affinity for DNA. We evaluated the OSX ability to bind to Sp1/GC-rich sequences (which have been shown to be OSX responsive elements ${ }^{12,26}$ by performing an oligo-pull-down assay using a sequence of the bone enhancer from the Col1a1 promoter. ${ }^{26}$ We expressed OSX in Trp53 knockout osteoblasts using retrovirus and tested the affinity of OSX for the oligonucleotide. Co-infection with a murine wild-type p53 retrovirus led to a 60-70\% lower OSX binding affinity for the Sp1/GC-rich sites (Figure 4a). We also co-infected the p53-deficient osteoblasts with the transcriptionally inactive human p53R273H mutant. Co-expression of this mutant also reduced OSX binding to the oligonucleotide, which refutes the possibility of a p53-dependent transcriptional mechanism underlying OSX binding inhibition (Figure $4 \mathrm{a}$ ). These results in vitro were confirmed by chromatin immunoprecipitation (ChIP) in SaOs2, where expression of wild-type p53 reduced OSX and RUNX2 occupancy in the responsive regions of the promoter of their target genes IBSP, COL1A1 and BGLAP (Figure 4b). Expression of the human p53R273H mutant also reduced recruitment of OSX to IBSP,COL1A1 and BGLAP promoters, whereas OSX binding was not significantly reduced by p53P275S (Figure 4b).

In accordance with it, the expression levels of the OSX target genes were repressed by the presence of murine wildtype p53 and the human p53R273H contact mutant in Trp53 knockout osteoblast (Figure 4c). However, p53P275S failed to induce repression of these genes. To verify the mechanism that confers differential inhibition of OSX activity by distinct p53 mutants, we analyzed the physical interaction of OSX with wild-type p53, and the R273H and P275S mutants. Purification of OSX from extracts of SaOs2 cells retrovirally expressing Osx and p53 mutants demonstrate that physical interaction between OSX and p53P275S was reduced compared with the interaction with wild type and R273H mutant (Figure 4d). These results confirm that the effects on OSX transcriptional activity are not dependent on p53 transcriptional activity, but on protein-protein interaction. Together, these data suggest regulation of OSX transcriptional activity by $\mathrm{p53}$ at protein level via blockage of the OSX interaction with their Sp1/GC-rich responsive sites.

The OSX interaction network is inhibited by p53. It has recently been described that OSX acts as a cofactor for the DLX transcription factor family. ${ }^{10}$ As p53 binds close to the OSX zinc-finger domain implicated in the OSX-DLX5 interaction, we investigated the impact of p53 binding on the OSX-DLX5 complex. First, we analyzed whether p53 could disrupt the OSX-DLX5 complex. We performed GSTDLX5 pull-down assays using extracts from SaOs2-p53TetOn cells infected with murine wild-type p53 or the human $\mathrm{R} 273 \mathrm{H}$ mutant. As previously described OSX bound DLX5, ${ }^{10}$ but both wild type p53 and the R273H mutant disrupted this interaction (Figure 5a). Thus, p53 could likely inhibit OSX transcriptional activity in promoters regulated by the OSXDLX complex.

As mentioned before, OSX is able to regulate its own promoter $^{31}$ and our group had also previously identified DLX5 as an activator of the proximal promoter of Osx. ${ }^{11}$ The Osx promoter $-114 /-51$ contains a Sp1/GC-rich box that could be a target for direct OSX binding, as well as a DLX5-binding homeobox. Luciferase assays using this Osx promoter region showed that both OSX and DLX5 activated the Osx promoter, and they showed an additive effect when expressed together (Figure 5b). More importantly, activation of the Osx promoter was repressed by p53. Mutation of either the homeobox or the Sp1/GC-rich sequences reduced the ability of DLX5 and OSX to activate transcription from the Osx promoter, suggesting that both sites are relevant for their function. To further discern whether the inhibition of p53 on the Osx promoter is through inhibition of OSX binding to the GC-rich box or instead by avoiding its role as a DLX5 cofactor, we performed an oligopull-down assay using the $-114 /-51$ Osx promoter. We tested the capacity of OSX and DLX5 to bind to the wild-type $-114 /-51$ sequence ( $\mathrm{pOsx} \mathrm{HB}-\mathrm{wt}$ ), or to the sequence with the homeobox site mutated (pOsx HB-mut) (Figure 5c). Assays from doxycycline-treated SaOs2-p53TetOn cells confirmed that OSX was able to bind to this promoter region probably using the Sp1/GC-rich box, besides binding to the homeobox, given that OSX was still able to bind to the HB-mut oligonucleotide. As expected, DLX5 bound to the HB-wt and showed lower affinity to the HB-mut oligonucleotide. The presence of p53 not only reduced OSX binding to both sequences but also blocked the binding of DLX5 to the homeobox site. These results were confirmed by chromatinimmunoprecipitation in SaOs2-p53TetOn cells, where induction of p53 strongly reduced DLX5 occupancy in the OsX promoter (Figure $5 \mathrm{~d}$ ). Therefore, binding of both DLX5 and OSX to their sites were inhibited by $\mathrm{p} 53$. Altogether, our results suggest a novel mechanism of OSX regulation, as summarized in Figure 6. p53 inhibits OSX transcriptional and osteogenic activity by binding close to its zinc-finger region, repressing its interaction with DNA and its transcriptional partners, such as DLX5.

\section{Discussion}

Cell differentiation and proliferation are usually thought of as antagonistic events in many cell types, with differentiation being only possible after blockage of proliferation. As a canonical tumour suppressor, p53 is supposed to inhibit proliferation but also promote differentiation. ${ }^{36}$ However, the inhibitory role of p53 in osteogenic differentiation, in a cellautonomous manner, is well established by mouse genetics and cell-based approaches. ${ }^{19}$ Although the p53-null mouse shows enhanced bone mineral density, Mdm2-conditional knockout results in a severe impairment of bone formation. ${ }^{17,24}$ Interestingly, MSCs derived from induced pluripotent stem cells from Li-Fraumeni patients carrying the transcriptionally inactive p53G245D mutation showed deficient osteoblast differentiation. Moreover, deletion of p53 in these iPS cells eliminated the osteogenic differentiation defect suggesting that osteogenic effects are derived from gain-offunction activities of mutant $\mathrm{p} 53$. $^{37}$ 
Despite this evidence, the exact nature of the mechanisms that underlie these p53 effects remained unknown. Our work identifies these effects on osteoblast differentiation through repression of OSX activity by direct interaction with p53. Previous studies focused on the impact of the p53 family over osteogenic BMP signalling with interesting findings such as a

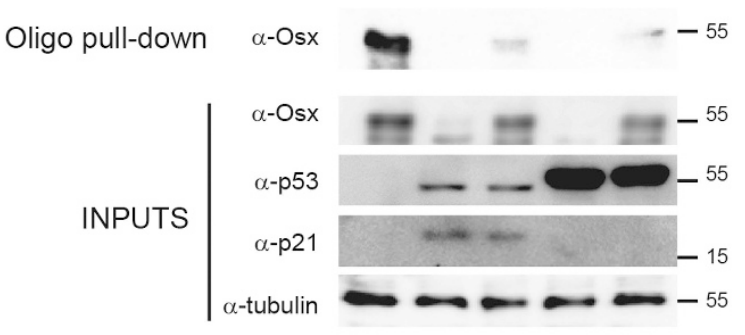

$+\quad+-\quad+$ Osx
- + + - - p53 wt

$-\quad+\quad+\quad+$ p53R273H

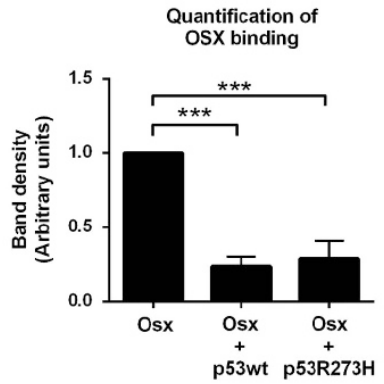

b

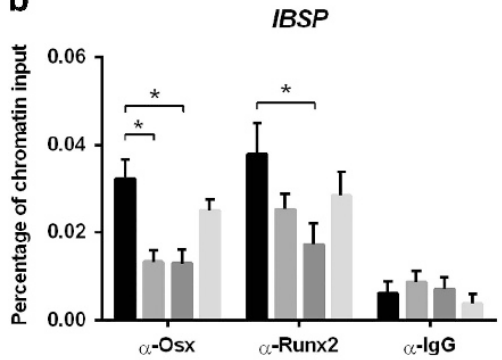

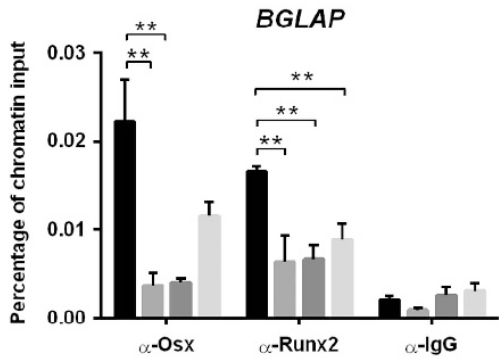

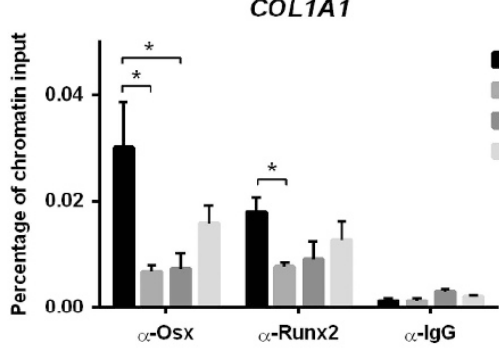

Untreated p53 wt p53 R273H p53 P275S

C

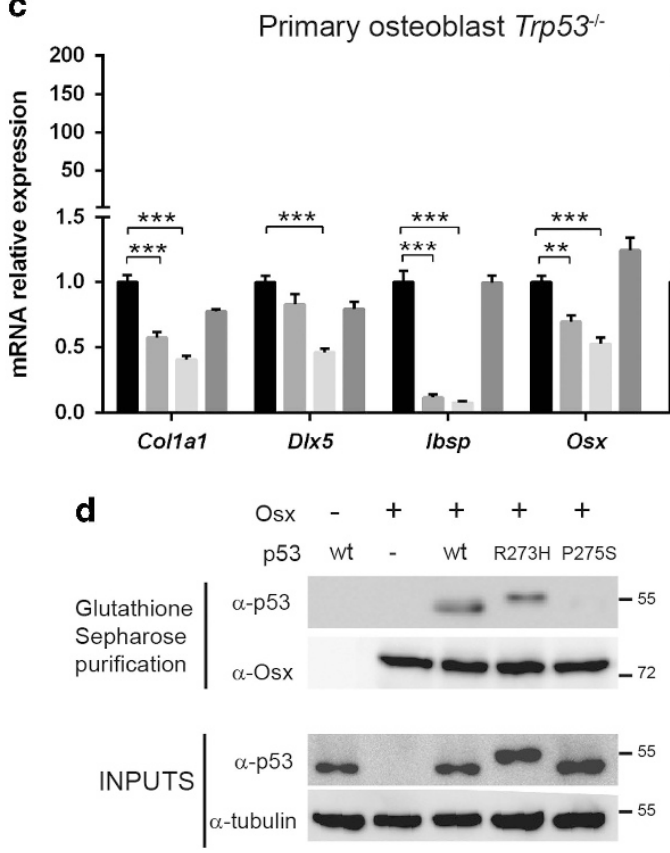

Figure 4 p53 blocks OSX binding to Sp1 elements. (a) Oligo-pull-down assay was performed using a biotinylated-oligonucleotide containing the Col1a1 bone-enhancer sequence. The oligonucleotide was incubated with extracts from Trp53 knockout primary osteoblasts retrovirally infected with the indicated expression vectors. Bar graph on the right shows the quantification of the OSX band after streptavidin-purification relative to their input levels. (b) ChIP from SaOs2 cells infected with retroviral expression vectors for murine p53 wild-type, human p53R273H and murine p53P275S. DNA-protein complexes were isolated with antibodies against Osx, Runx2 and lgG. Specific primers for the promoters of IBSP, BGLAP (Osteocalcin) and COL1A1 bone-enhancer were used for qRT-PCR analysis. Results are represented relative to input chromatin. (c) Trp53 knockout primary osteoblasts were retrovirally infected with murine p53 wild-type or p53P275S or human p53R273H mutant forms. p21 gene was used as reporter of p53 transcriptional activity. mRNA was measured by qRT-PCR, normalized to Tbp and expressed as relative expression \pm S.E.M. of at least three independent experiments $\left({ }^{*} P<0.05\right.$, ${ }^{\star *} P<0.01$, ${ }^{* * *} P<0.001$, using Student's $t$-test). (d) SaOs2 cells were infected with retrovirus expression vectors for murine GST-tagged Osx and p53 wild-type and P275S from mouse or human p53R273H. Extracts from SaOs2 cells and Glutathione-Sepharose co-precipitated proteins were visualised by immunoblotting using anti-p53 and anti-Osx antibodies 
a

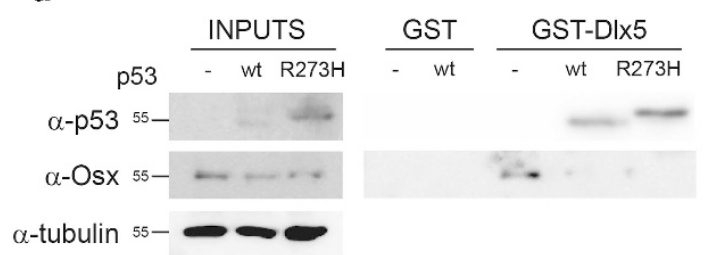

b
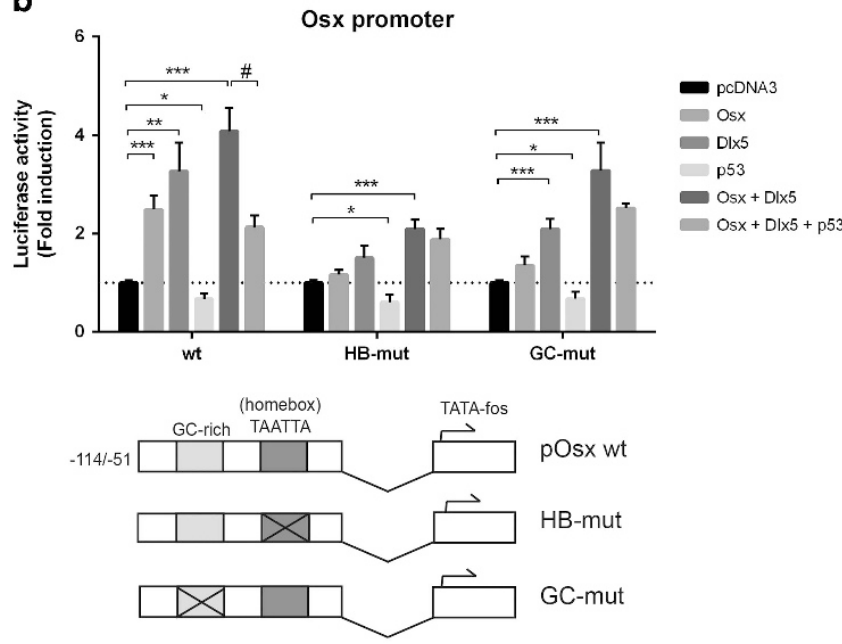
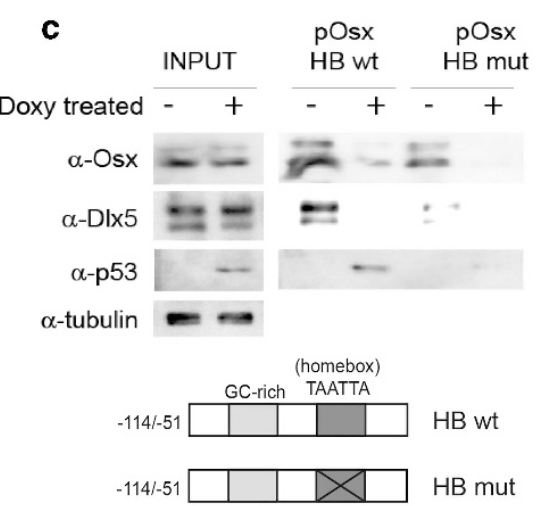

d

DLX5 occupancy at OSX promoter

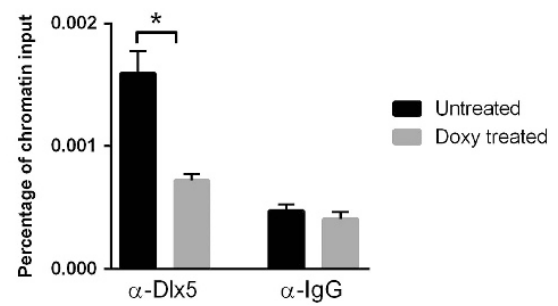

Figure 5 Inhibition of Osx promoter is mediated by p53 blocking DLX5-OSXx complex. (a) Extracts of SaOs2-p53TetOn retrovirally infected with the indicated p53-expression vectors were incubated with the indicated chimeric protein bound to Glutathione-Sepharose beads overnight. Interacting proteins were identified by immunoblotting using anti-Osx and anti-p53 antibodies. (b) SaOs2 cells were co-transfected with the indicated expression vectors, or empty pcDNA3 vector as control, and the murine - 114/ - 51 Osterixpromoter luciferase reporter, wild-type or with the indicated mutated versions. HB-mut is the reporter with the homeodomain box mutated; GC-mut indicates mutation in the Sp1/ GC-rich box. ${ }^{11}$ Scheme of the $-114 /-51$ Osterix-promoter is shown. Luciferase activity was measured and normalized against $\beta$-galactosidase activity, and represented as fold induction compared with the pcDNA3 transfection condition. \# is used to compare Osx+Dlx5 versus Osx+D|x5+p53 conditions. (c) Oligo-pull down using biotinylated $-114 /-51$ Osterix-promoter sequence ( $\mathrm{pOsx} \mathrm{HB}$ wt) and its homeobox-mutated version ( $\mathrm{pOsx} \mathrm{HB}$ mut). Extracts from SaOs2-p53TetOn untreated or treated for $24 \mathrm{~h}$ with $2 \mathrm{nM}$ doxycycline were used. Interacting proteins were identified by immunoblotting using anti-OSX, anti-DLX5 and anti-p53. (d) SaOs2-p53TetOn were treated or not with $2 \mathrm{nM}$ doxycycline for $24 \mathrm{~h}$. DNA-protein complexes were isolated with antibodies against DLX5 and IgG. Specific primers for the Osx promoter were used for qRT-PCR analysis. Results are represented relative to input chromatin from three independent experiments $\left({ }^{*} P<0.05\right)$

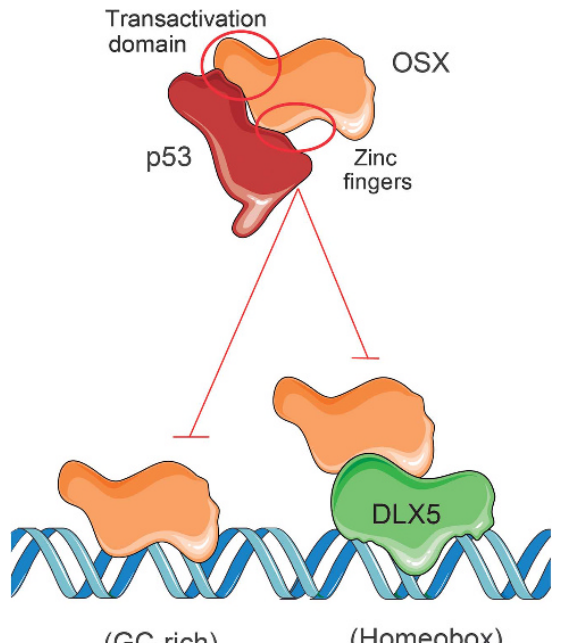

(GC-rich)

Figure 6 Schematic representation of the proposed p53-OSX network: p53 blocks Osterix transcriptional activity by physical interaction. We suggest that p53OSX interaction prevents OSX from binding to Sp1/GC-rich sequences, and also interferes in the formation of the OSX-DLX5 transcriptional complex, that responds to homeobox sequences

the p53-Smad1/5 physical interaction, ${ }^{38}$ or Smad1 upregulation due to the lack of $p 53 .{ }^{16,20}$ Our data suggest that these changes were of low magnitude. We also identified positive regulation of the gene expression of the Smad signalling inhibitor Smad7. These data are in agreement with data from epithelial cells, which establishes that p53 family members bind to the Smad7 promoter through a p53-response element. ${ }^{39}$

As mentioned above, our work and previous studies revealed that p53 represses the expression of osteoblastdetermining transcription factors independently of p53-DNA binding. ${ }^{17,37}$ Our data further demonstrated the ability of $p 53$ to inhibit the transcriptional osteogenic programme independent of p53-DNA binding on the basis of several lines of evidence. First, a transcriptionally inactive mutant form of human p53 $(\mathrm{R} 273 \mathrm{H})$ similarly blocked OSX function, whereas a murine conformational mutant (P275S) had lower inhibitory ability. Second, RUNX2-deficient osteoblasts were also sensitive to the inhibitory effects of p53. Third, p53 was able to repress binding to DNA and cooperative transcriptional effects of endogenous and ectopic OSX and DLX5.

Osx, Runx2 and DIx5 are mandatory transcriptional regulators of the osteogenic process. Their gene products 
physically interact and lead to a strong cooperation in the transcription of target genes and the production of a mineralized bone matrix. ${ }^{9,10}$ Previous studies also depict an integrative feed-forward transcriptional network involving Runx2, Osx and DIx5, in which they positively regulate each other's transcription. $9,11,40-43$ These fully integrated relationships suggest that any alteration in the function of any of them would result in a de-regulation of the whole network. Thus, the p53-mediated inhibition of OSX function could be an important factor in the maintenance of bone homeostasis under physiological conditions. p53 signalling mutations, which lead to high p53 protein expression levels, ${ }^{44,45}$ would disturb the function of the DIx5-Runx-Osx network with important consequences.

The DNA-binding domain of p53 interacts with an OSX domain adjacent to its zinc fingers. Similarly, we also mapped the PST transactivation domain of RUNX2 as its p53interaction region. Interaction between p53 and OSX results in downregulation of Osx target genes involved in bone matrix maturation, such as Ibsp, Col1a1 and Osx itself. The Osx proximal promoter, the first known molecular target of p53 inhibition, ${ }^{17}$ is positively controlled through direct DNA binding by OSX and DLX5 proteins. ${ }^{11,27,31}$ We determined that $\mathrm{p} 53$ interaction does not alter OSX localization but impairs OSXDNA binding in vitro and in vivo to their canonical Sp1/GC-rich sites. Moreover, p53 also inhibits OSX-DLX5 transcriptional complex formation and binding to homeobox sequences. Importantly, the OSX-DLX5 complex co-occupy most the bone enhancer regions in genome-wide analysis and evolutionary analysis showed correlation with the evolution of skeletal formation. ${ }^{10}$ As p53 and DLX5 share the region of interaction with $\mathrm{OSX},{ }^{10}$ it is plausible to infer that higher levels of p53 would abrogate OSX-DLX5 complex formation. By blocking these two DNA-binding mechanisms of action of OSX, p53 breaks two important mechanisms of the osteoblast transcriptional programme.

Our findings that $\mathrm{p} 53$ has a transcriptionally independent role in OSX function suggest important physiopathological consequences. Proliferation and differentiation should coexist in a coordinated manner to maintain tissue homeostasis over time. Besides its major role in the transcriptional control of proliferation and apoptosis, p53 might block osteogenic differentiation from mesenchymal precursors to allow its expansion and prevent their shortage from premature specification. Deregulation of these networks would lead to osteoporosis by shortage of mesenchymal precursors and/or misdirected differentiation towards alternative fates such as adipocytes, which are both characteristic features of ageing. ${ }^{46}$ Several reports indicate that loss of osteogenic potential and increased adipogenesis of bone progenitors during senescence is dependent on p53 and correlated with lower Osx expression. ${ }^{47}$ Moreover, the shift from osteoblastogenesis to increased adiposity observed in osteopenias induced by ageing, accelerated senescence or ovariectomy correlated with upregulation of p53 levels. ${ }^{46}$

The relation between p53 mutations and osteosarcomagenesis has been highlighted in several studies. ${ }^{36,48,49}$ Osteosarcoma is largely composed of poorly differentiated cells ${ }^{50}$ and the p53 loss-of-function is enough for the development of osteosarcoma. ${ }^{51}$ Previous studies, aimed at detecting the origin of the osteosarcoma, point to dedifferentiated osteoblastic cells, rather than MSCs. ${ }^{36,37,49,50}$ In addition, most p53 mutations are missense and impair DNA binding, but give rise to the gain of new oncogenic functions. ${ }^{52,53}$ Our data suggest a possible negative correlation between p53 and OSX protein levels that varies depending on p53 specific mutation (Figure 3d). Therefore, the definition of p53 status and its mutation in osteosarcomas likely could help us to understand its effect on osteogenic differentiation, and to better tackle the progression of the disease. Altogether, our data support a model where p53 represses OSX-DNA binding and OSXDLX5 interaction and thereby deregulates the osteogenic transcriptional network.

\section{Materials and Methods}

Mouse model. Trp53 knockout mice B6.129S2-Trp53tm1Tyj/J from Jackson Laboratories (Bar Harbor, ME, USA) were kindly provided by Dr J Martin-Caballero. Mice were housed under controlled conditions $\left(12 \mathrm{~h}\right.$ light $/ 12 \mathrm{~h}$ dark cycle, $21^{\circ} \mathrm{C}$, $55 \%$ humidity) and fed ad libitum with water and a 14\% protein diet (Teklad 2014, Harlan, Santa Perpètua de Mogoda, Barcelona, Spain). All animal experiments were performed in accordance with guidelines approved by the Ethical Committee for Animal Experimentation of the University of Barcelona and Generalitat de Catalunya (Spain).

Cell culture. SaOs2-p53TetOn, kindly provided by Dr R Bartrons, and HEK293T (American Type Culture Collection, Rockville, MD, USA) cell lines were maintained in DMEM supplemented with 10\% fetal bovine serum (FBS), $2 \mathrm{mM}$ glutamine, $1 \mathrm{mM}$ pyruvate, $100 \mathrm{U} / \mathrm{ml}$ penicillin and $0.1 \mathrm{mg} / \mathrm{ml}$ streptomycin. The isolation of primary osteoblasts from calvaria was carried out as described previously. ${ }^{54}$ Primary osteoblasts and H1-127-30 osteoblast cell line ${ }^{32}$ were maintained in $\alpha$-MEM supplemented with $10 \% \mathrm{FBS}, 2 \mathrm{mM}$ glutamine, $1 \mathrm{mM}$ pyruvate, $100 \mathrm{U} / \mathrm{ml}$ penicillin and $0.1 \mathrm{mg} / \mathrm{ml}$ streptomycin. As osteogenic differentiation medium, osteoblast medium was supplemented with $50 \mu \mathrm{M}$ ascorbic acid and $10 \mathrm{mM} \beta$-glycerophosphate. HEK293T cells were transiently transfected using polyethylenimine, and SaOs2 using Lipofectamine-LTX (Invitrogene). Retroviral infection in Trp53 knockout osteoblasts, $\mathrm{H1}-127-30$ and SaOs2 cells were performed as described previously. ${ }^{55}$ Doxycycline treatment $(2 \mathrm{nM}$ ) was carried out in media with $1 \%$ FBS. BMP2 (R\&D, Minneapolis, MN, USA) was used at $2 \mathrm{nM}$.

CRISPR-Cas9. The RUNX2 gene was knocked down in SaOs2 cells using the system described by Ran et $a^{56}{ }^{56}$. The gRNA sequence was designed to target the exon 3 of the RUNX2 gene. The guide sequence was cloned into the pSpCas9(BB)$2 A-P u r o$ vector donated by $R$. Estevez and confirmed by sequencing. The primers used were: F:5'CACCGGCTGGTGCTCGGATCTACGG3' and R:5'-AAACCCG TAGATCCGAGCACCAGCC-3'. SaOs2 cells were plated in six wells and transfected overnight. An empty vector without gRNA was used as negative control. Puromycin was added at $1 \mu \mathrm{g} / \mathrm{ml}$ and maintained three days for selection. The selected cells were tested for RUNX2 gene deletion by endonuclease assay. The following primers were used for RUNX2 amplification: F:5'-CAAACTTGATTTCTCACCTCCTCA-3' and R:5'-TTCAAGGTAAGAGGCTACACCGC-3'. The positive pools were expanded and checked for RUNX2 knock-down by immunoblot.

Plasmids and reagents. Murine Osterix expression vectors were kindly provided by Dr B de Crombrugghe. The Osx S73A/S77A, GST-Osx, GST-Osx $\Delta 346$ and GST-Osx $\Delta 155$ GST-Dlx5 were previously described, ${ }^{9,12}$ and GST-Osx $\Delta 58$, GST-Osx $\Delta 1-57$ and GST-Osx $\Delta 1-230$ were generated by double digestion from GST-Osx. GST-Runx2 and GST-Runx2 230 were kindly provided by $\mathrm{Dr} M$ Montecino. The GST-p53 and their derivatives were kindly provided by $\operatorname{Dr} Y$ Xiong. The human His-p53-(1-320) and His-p53-(94-312) were a gift from Dr Arrowsmith (Addgene plasmid 24864 and 24866, respectively). The pMXs-p53 and pMXs-p53P275S from mouse were a gift from Dr Yamanaka (Addgene plasmids 22725 and 22726, respectively). ${ }^{57}$ The pMXs-p53R273H was generated from pLenti6/V5-p53_R273H (from Dr Futscher, Addgene plasmid 22934) (8) $^{58}$ subcloning the human p53R272H sequence into pMXs plasmid. Human pMXsOsx was a gift from Dr O Mazda. The pBABE-GST-p53 retroviral expression vector 
was generated from pEBG-GST-p53. The pBABE-GST-OSX was generated from pGEX-OsX.

Pull-down assays. For in vitro GST-pull down experiments, the assays were performed as described previously. ${ }^{9}$ For analysis of the physical interaction assays in mammalian cells, the GST-p53 or the GST-Osx vectors were co-transfected with Osx or the distinct p53 mutant expression vectors in HEK293T or retrovirally infected in SaOs2 cells and cells were lysed after $48 \mathrm{~h}$. Lysates were collected, centrifuged to eliminate debris and purified by binding to Glutathione-Sepharose beads for $1 \mathrm{~h}$ at $4{ }^{\circ} \mathrm{C}$. Then, the beads were washed with washing buffer $(50 \mathrm{mM}$ Tris/ $\mathrm{HCl}$, $150 \mathrm{mM} \mathrm{NaCl}, 0.1 \%$ Igepal-CA630 plus protease and phosphatase inhibitors) three times. Bound proteins were detected by immunoblotting. For in vitro pull down of His-tagged proteins, all used buffers were supplemented with $10 \mathrm{mM}$ imidazol and bound to $\mathrm{Ni}^{2+}$ resin for purification.

Luciferase assay. SaOs2 cells were cultured in 24-well plates and transfected for $8 \mathrm{~h}$ with Lipofectamine LTX with the indicated plasmids. Transfection efficiency was assessed by GFP expression. Luciferase activities were quantified $48 \mathrm{~h}$ posttransfection using the Luciferase assay system (Promega, Madison, WI, USA) and normalized using the $\beta$-Galactosidase Detection Kit II (Clontech, Mountain View, CA, USA).

Oligo-pull-down assays. Oligo-pull-down assays were carried out as previously described. ${ }^{26}$ The pOsx HB-wt and pOsx HB-mut oligonucleotides were generated by PCR using biotinylated primers from the proximal Osterix murine promoter, and wild-type or homeobox-mutated $-114 /-51$ Osterix promoter sequences as templates. The $\mathrm{Sp} 1$ oligonucleotide sequence was generated from the Col1a1 promoter as previously described. ${ }^{26}$

Western blot assay. Identification of proteins, from cell extracts or pull-down assays, was performed by immunoblotting against phospho-Smad1/5/8, Smad1 (Cell Signaling 9743 and 13820, Danvers, MA, USA), Osx (Abcam 22552, Cambridge, UK), Runx2 (MBL D130-3, Woburn, MA, USA), p53 (Cell Signaling 48818), Id1 (C-20 sc-488) and p21 (C-19 sc-397) (Santa Cruz Biotechnology, Dallas, TX, USA) or $\alpha$-tubulin (Sigma-Aldrich T5168, St. Louis, MO, USA), diluted at 1: 1000. Antibodies against Dlx5 (C-20 sc-18152 and Y-20 sc-18151) (Santa Cruz Biotechnology) were used at 1:500. Immunoreactive bands were detected with horseradish-peroxidase-conjugated secondary antibodies and an ECL-kit (Biological Industries, Cromwell, CT, USA).

ChIP assay. ChIP assay was carried out as described in Artigas et al. ${ }^{9}$. SaOs 2 p53TetOn cells were cultured until confluence before overnight doxycycline treatment. $\mathrm{SaOs}_{2}$ were retrovirally infected with the distinct p53 mutant constructs. ChIP was carried out using $1 \mu \mathrm{g}$ of the indicated antibodies: anti-Osx (Abcam), antiRunx2 (MBL), anti-Dlx5 (C-20 sc-18152 and Y-20 sc-18151, $0.5 \mu \mathrm{g}$ each) or antiIgG (Upstate) as a control, and purified with $20 \mu \mathrm{l}$ Magna ChIP Protein $A+G$ Magnetic Beads (Millipore, Billerica, MA, USA). The DNA fragments were purified using the QIAquick Gel Extraction Kit (Qiagen, Hilden, Germany) and analyzed by qRT-PCR. The primers used for the qRT-PCR analysis for IBSP and COL1A1 were previously described. ${ }^{9}$ BGLAP primers were R: 5'-CCGTAGGCCAAACCCCAG AGGATATGT-3' and F: $5^{\prime}$-CTCTGCTTGAACCTATTTTAGGTCTCTGA-3'. OSX primers were: R: $5^{\prime}$-CCTGCTTCCCACCCCTTCCA-3' and F: $5^{\prime}$-ATGAGGAGG GCGAGAGAGGG-3'.

Immunocytofluorescence. SaOs2 p53TetOn immunofluorescence was performed as previously described ${ }^{9}$ using 1:100 p53 (Cell Signaling) and 1:250 anti-Osterix (Abcam).

qRT-PCR analysis. Total RNA was isolated from primary osteoblasts or SaOs2 cells using TRIsure reagent (Bioline, London, UK). Purified RNA was reverse-transcribed using the High-Capacity cDNA Reverse Transcription Kit (Applied Biosystems, Foster City, CA, USA). Quantitative PCRs were carried out using the ABI Prism 7900 HT Fast Real-Time PCR System and Taqman 5'. nuclease probes (Applied Biosystems). Designed Taqman assays (Applied Biosystems) were used to quantify gene expression. All transcripts were normalized to Tbp expression.
Statistical analysis. Statistical analysis was performed using the Student's $t$-test. Quantitative data are presented as means \pm S.E.M. Differences were considered significant at ${ }^{*} P<0.05,{ }^{* *} P<0.01$ and ${ }^{* * *} P<0.001$.

\section{Conflict of Interest}

The authors declare no conflict of interest.

Acknowledgements. We thank Drs B de Crombrugghe, J Martín-Caballero, M Montencino, Y-Xiong and HM Ryoo for reagents. We also thank E Adanero, E Castaño and B Torrejón for technical assistance. Natalia Artigas is the recipient of a fellowship from University of Barcelona. This research was supported by grants from the M.E.C. (BFU2014-56313-P) and La Marató de TV3.

1. Long F. Building strong bones: molecular regulation of the osteoblast lineage. Nat Rev Mol Cell Biol 2011; 13: 27-38.

2. Karsenty G, Kronenberg HM, Settembre C. Genetic control of bone formation. Annu Rev Cell Dev Biol 2009; 25: 629-648.

3. Sinha KM, Zhou X. Genetic and molecular control of osterix in skeletal formation. J Cell Biochem 2013; 114: 975-984.

4. Ducy P, Zhang R, Geoffroy V, Ridall AL, Karsenty G. Osf2/Cbfa1: a transcriptional activator of osteoblast differentiation. Cell 1997; 89: 747-754.

5. Zhou X, Zhang Z, Feng JQ, Dusevich VM, Sinha K, Zhang $\mathrm{H}$ et al. Multiple functions of Osterix are required for bone growth and homeostasis in postnatal mice. Proc Natl Acad Sci USA 2010; 107: 12919-12924.

6. Baek WY, de Crombrugghe B, Kim JE. Postnatally induced inactivation of Osterix in osteoblasts results in the reduction of bone formation and maintenance. Bone 2010; 46: 920-928.

7. Timpson NJ, Tobias JH, Richards JB, Soranzo N, Duncan EL, Sims AM et al. Common variants in the region around Osterix are associated with bone mineral density and growth in childhood. Hum Mol Genet 2009; 18: 1510-1517.

8. Lapunzina P, Aglan M, Temtamy S, Caparros-Martin JA, Valencia M, Leton R et al. Identification of a frameshift mutation in Osterix in a patient with recessive osteogenesis imperfecta. Am J Hum Genet 2010; 87: 110-114.

9. Artigas N, Urena C, Rodriguez-Carballo E, Rosa JL, Ventura F. Mitogen-activated protein kinase (MAPK)-regulated interactions between Osterix and Runx2 are critical for the transcriptional osteogenic program. J Biol Chem 2014; 289: 27105-27117.

10. Hojo H, Ohba S, He X, Lai LP, McMahon AP. Sp7/osterix is restricted to bone-forming vertebrates where it acts as a Dlx co-factor in osteoblast specification. Dev Cell 2016; 37: 238-253.

11. Ulsamer A, Ortuno MJ, Ruiz S, Susperregui AR, Osses N, Rosa JL et al. BMP-2 induces Osterix expression through up-regulation of Dlx5 and its phosphorylation by p38. J Biol Chem 2008; 283: 3816-3826.

12. Ortuno MJ, Ruiz-Gaspa S, Rodriguez-Carballo E, Susperregui AR, Bartrons R, Rosa JL et al. 338 regulates expression of osteoblast-specific genes by phosphorylation of osterix. J Biol Chem 2010; 285: 31985-31994.

13. Greenblatt MB, Shim JH, Zou W, Sitara D, Schweitzer M, Hu D et al. The p38 MAPK pathway is essential for skeletogenesis and bone homeostasis in mice. J Clin Invest 2010; 120: 2457-2473.

14. Carvajal LA, Manfredi JJ. Another fork in the road-life or death decisions by the tumour suppressor p53. EMBO Rep 2013; 14: 414-421.

15. Molchadsky A, Shats I, Goldfinger N, Pevsner-Fischer M, Olson M, Rinon A et al. p53 plays a role in mesenchymal differentiation programs, in a cell fate dependent manner. PLOS ONE 2008; 3: e3707.

16. Liu H, Jia D, Li A, Chau J, He D, Ruan X et al. p53 regulates neural stem cell proliferation and differentiation via BMP-Smad1 signaling and Id1. Stem Cells Dev 2013; 22: 913-927.

17. Wang $X$, Kua HY, Hu Y, Guo K, Zeng Q, Wu Q et al. p53 functions as a negative regulator of osteoblastogenesis, osteoblast-dependent osteoclastogenesis, and bone remodeling. J Cell Biol 2006; 172: 115-125.

18. Armstrong JF, Kaufman MH, Harrison DJ, Clarke AR. High-frequency developmental abnormalities in p53-deficient mice. Curr Biol 1995; 5: 931-936.

19. He Y, de Castro LF, Shin MH, Dubois W, Yang HH, Jiang $S$ et al. p53 loss increases the osteogenic differentiation of bone marrow stromal cells. Stem Cells 2015; 33: 1304-1319.

20. Ruan X, Zuo Q, Jia H, Chau J, Lin J, Ao J et al. P53 deficiency-induced Smad1 upregulation suppresses tumorigenesis and causes chemoresistance in colorectal cancers. J Mol Cell Biol 2015; 7: 105-118.

21. Liu W, Qi M, Konermann A, Zhang L, Jin F, Jin Y. The p53/miR-17/Smurf1 pathway mediates skeletal deformities in an age-related model via inhibiting the function of mesenchymal stem cells. Aging (Albany NY) 2015; 7: 205-218.

22. Ozaki T, Wu D, Sugimoto $H$, Nagase $H$, Nakagawara A. Runt-related transcription factor 2 (RUNX2) inhibits p53-dependent apoptosis through the collaboration with HDAC6 in response to DNA damage. Cell Death Dis 2013; 4: e610. 
23. van der Deen M, Taipaleenmaki H, Zhang Y, Teplyuk NM, Gupta A, Cinghu S et al. MicroRNA-34c inversely couples the biological functions of the runt-related transcription factor RUNX2 and the tumor suppressor p53 in osteosarcoma. J Biol Chem 2013; 288: 21307-21319.

24. Lengner CJ, Steinman HA, Gagnon J, Smith TW, Henderson JE, Kream BE et al. Osteoblast differentiation and skeletal development are regulated by Mdm2-p53 signaling. J Cell Biol 2006; 172: 909-921.

25. Nakashima K, Zhou X, Kunkel G, Zhang Z, Deng JM, Behringer RR et al. The novel zinc finger-containing transcription factor osterix is required for osteoblast differentiation and bone formation. Cell 2002; 108: 17-29.

26. Ortuno MJ, Susperregui AR, Artigas N, Rosa JL, Ventura F. Osterix induces Col1a1 gene expression through binding to Sp1 sites in the bone enhancer and proximal promoter regions. Bone 2013; 52: 548-556.

27. Yang $Y$, Huang $Y$, Zhang L, Zhang $C$. Transcriptional regulation of bone sialoprotein gene expression by Osx. Biochem Biophys Res Commun 2016; 476: 574-579.

28. Chen H, Hays E, Liboon J, Neely C, Kolman K, Chandar N. Osteocalcin gene expression is regulated by wild-type p53. Calcif Tissue Int 2011; 89: 411-418.

29. Chen H, Kolman K, Lanciloti N, Nerney M, Hays E, Robson C et al. p53 and MDM2 are involved in the regulation of osteocalcin gene expression. Exp Cell Res 2012; 318: 867-876.

30. Chau JF, Jia D, Wang Z, Liu Z, Hu Y, Zhang X et al. A crucial role for bone morphogenetic protein-Smad1 signalling in the DNA damage response. Nat Commun 2012; 3: 836.

31. Barbuto R, Mitchell J. Regulation of the osterix (Osx, Sp7) promoter by osterix and its inhibition by parathyroid hormone. J Mol Endocrinol 2013; 51: 99-108.

32. Lee KS, Kim HJ, Li QL, Chi XZ, Ueta C, Komori T et al. Runx2 is a common target of transforming growth factor beta1 and bone morphogenetic protein 2, and cooperation between Runx2 and Smad5 induces osteoblast-specific gene expression in the pluripotent mesenchymal precursor cell line C2C12. Mol Cell Biol 2000; 20: 8783-8792.

33. de Vries A, Flores ER, Miranda B, Hsieh HM, van Oostrom CT, Sage J et al. Targeted point mutations of p53 lead to dominant-negative inhibition of wild-type p53 function. Proc Natl Acad Sci USA 2002; 99: 2948-2953.

34. Chen Y, Dey R, Chen L. Crystal structure of the p53 core domain bound to a full consensus site as a self-assembled tetramer. Structure 2010; 18: 246-256.

35. Cho Y, Gorina S, Jeffrey PD, Pavletich NP. Crystal structure of a p53 tumor suppressor-DNA complex: understanding tumorigenic mutations. Science 1994; 265: 346-355.

36. Kruiswijk F, Labuschagne CF, Vousden KH. p53 in survival, death and metabolic health: a lifeguard with a licence to kill. Nat Rev Mol Cell Biol 2015; 16: 393-405.

37. Lee DF, Su J, Kim HS, Chang B, Papatsenko D, Zhao R et al. Modeling familial cancer with induced pluripotent stem cells. Cell 2015; 161: 240-254.

38. Balboni AL, Cherukuri $\mathrm{P}$, Ung M, DeCastro AJ, Cheng C, DiRenzo J. p53 and DeltaNp63alpha coregulate the transcriptional and cellular response to TGFbeta and BMP signals. Mol Cancer Res 2015; 13: 732-742.

39. De Rosa L, Antonini D, Ferone G, Russo MT, Yu PB, Han R et al. p63 Suppresses nonepidermal lineage markers in a bone morphogenetic protein-dependent manner via repression of Smad7. J Biol Chem 2009; 284: 30574-30582.

40. Roca H, Phimphilai M, Gopalakrishnan R, Xiao G, Franceschi RT. Cooperative interactions between RUNX2 and homeodomain protein-binding sites are critical for the osteoblastspecific expression of the bone sialoprotein gene. J Biol Chem 2005; 280: 30845-30855.
41. Lee MH, Kim YJ, Yoon WJ, Kim JI, Kim BG, Hwang YS et al. Dlx5 specifically regulates Runx2 type II expression by binding to homeodomain-response elements in the Runx2 distal promoter. J Biol Chem 2005; 280: 35579-35587.

42. Nishio Y, Dong Y, Paris M, O'Keefe RJ, Schwarz EM, Drissi H. Runx2-mediated regulation of the zinc finger Osterix/Sp7 gene. Gene 2006; 372: 62-70.

43. Kawane $\mathrm{T}$, Komori $\mathrm{H}$, Liu W, Moriishi T, Miyazaki T, Mori $\mathrm{M}$ et al. Dlx5 and mef2 regulate a novel runx2 enhancer for osteoblast-specific expression. J Bone Miner Res 2014; 29: 1960-1969.

44. Muller PA, Vousden KH. p53 mutations in cancer. Nat Cell Biol 2013; 15: 2-8.

45. Vijayakumaran R, Tan KH, Miranda PJ, Haupt S, Haupt Y. Regulation of mutant p53 protein expression. Front Oncol 2015; 5: 284.

46. Sui B, Hu C, Liao L, Chen Y, Zhang X, Fu X et al. Mesenchymal progenitors in osteopenias of diverse pathologies: differential characteristics in the common shift from osteoblastogenesis to adipogenesis. Sci Rep 2016; 6: 30186

47. Despars G, Carbonneau CL, Bardeau P, Coutu DL, Beausejour CM. Loss of the osteogenic differentiation potential during senescence is limited to bone progenitor cells and is dependent on p53. PLOS ONE 2013; 8: e73206.

48. Velletri T, Xie N, Wang Y, Huang Y, Yang Q, Chen X et al. P53 functional abnormality in mesenchymal stem cells promotes osteosarcoma development. Cell Death Dis 2016; 7: e2015.

49. Quist T, Jin H, Zhu JF, Smith-Fry K, Capecchi MR, Jones KB. The impact of osteoblastic differentiation on osteosarcomagenesis in the mouse. Oncogene 2015; 34: 4278-4284.

50. Tang N, Song WX, Luo J, Haydon RC, He TC. Osteosarcoma development and stem cell differentiation. Clin Orthop Relat Res 2008; 466: 2114-2130.

51. Walkley CR, Qudsi R, Sankaran VG, Perry JA, Gostissa M, Roth SI et al. Conditional mouse osteosarcoma, dependent on p53 loss and potentiated by loss of Rb, mimics the human disease. Genes Dev 2008; 22: 1662-1676.

52. Muller PA, Vousden KH. Mutant p53 in cancer: new functions and therapeutic opportunities. Cancer Cell 2014; 25: 304-317.

53. Kim MP, Zhang Y, Lozano G. Mutant p53: multiple mechanisms define biologic activity in cancer. Front Oncol 2015; 5: 249

54. Rodriguez-Carballo E, Ulsamer A, Susperregui AR, Manzanares-Cespedes C, SanchezGarcia $\mathrm{E}$, Bartrons $\mathrm{R}$ et al. Conserved regulatory motifs in osteogenic gene promoters integrate cooperative effects of canonical Wnt and BMP pathways. J Bone Miner Res 2011 26: 718-729.

55. Gamez B, Rodriguez-Carballo E, Graupera M, Rosa JL, Ventura F. Class I PI-3-kinase signaling is critical for bone formation through regulation of SMAD1 activity in osteoblasts. J Bone Miner Res 2016; 31: 1617-1630.

56. Ran FA, Hsu PD, Wright J, Agarwala V, Scott DA, Zhang F. Genome engineering using the CRISPR-Cas9 system. Nat Protoc 2013; 8: 2281-2308.

57. Kitamura T, Koshino Y, Shibata F, Oki T, Nakajima H, Nosaka T et al. Retrovirus-mediated gene transfer and expression cloning: powerful tools in functional genomics. Exp Hemato 2003; 31: 1007-1014.

58. Junk DJ, Vrba L, Watts GS, Oshiro MM, Martinez JD, Futscher BW. Different mutant/wild-type p53 combinations cause a spectrum of increased invasive potential in nonmalignant immortalized human mammary epithelial cells. Neoplasia 2008; 10 $450-461$.

Supplementary Information accompanies this paper on Cell Death and Differentiation website (http://www.nature.com/cdd) 